\title{
Study on the Potential Use of Electrochromic Materials for Solar Energy Harvest in Brazil Market
}

\author{
Da Rosa, H. B. ${ }^{1}$, Ando Junior, O. H. ${ }^{1-2}$, Furtado, A. C. ${ }^{2}$, Spacek, A. D. ${ }^{1-3}$, Mota, J. M. ${ }^{1-3}$, Bilessimo, L. D. ${ }^{1}$, \\ Malfatti, C. F. ${ }^{3}$, Santana, M. V. F de ${ }^{4-5}$ \\ 1 School of Engineering \\ UFRGS, Federal University of Rio Grande do Sul \\ Av. Osvaldo Aranha, 103. Porto Alegre-RS (Brazil) \\ Phone/Fax number: +55 51 3308-31.29, e-mail: eng.henriqueborges@gmail.com; celia.malfatti@ufrgs.br \\ ${ }^{2}$ Renewable Energy Engineering \\ UNILA, Federal University of Latin American Integration \\ Avenida Silvio Américo Sasdelli, 1842 - Vila A, Foz do Iguaçu - PR (Brazil) \\ Phone/Fax number: + 55 (45) 3576-7307, e-mail: oswaldo.junior@unila.edu.br, andreia.furtado@unila.edu.br
}

\author{
${ }^{3}$ Departament of Mechanic and Automation \\ SATC, Beneficent Association of Santa Catarina Coal Industry \\ Street Pascoal Meller, 73. Criciúma-SC (Brazil) \\ Phone/Fax number: +55 48 3431-75.50, e-mail: anderson.spacek@satc.edu.br, joao.neto@satc.edu.br, \\ luciano.bilessimo@satc.edu.br \\ ${ }^{4}$ Hidroelectric Power Plant \\ BAESA, Energética Barra Grande S/A \\ Rua Madre Benvenuta, 1168. Florianópolis-SC (Brazil) \\ Phone/Fax number: +55 48 3331-0000, e-mail: marcus.santana@ cscenergia.com.br \\ ${ }^{5}$ Hidroelectric Power Plant \\ ENERCAN, Campos Novos Energia S.A. \\ Rua Madre Benvenuta, 1168. Florianópolis-SC (Brazil) \\ Phone/Fax number: +55 48 3331-0000, e-mail: marcus.santana@cscenergia.com.br
}

\begin{abstract}
This paper presents a review of the characteristics of electrochromic materials, the concepts developed in recent years, the trends and forms of applications of these materials. The purpose of this paper consists in the use of an electrochromic material such as diffusion component and thermal / light control in a tubular system of natural lighting. The interest in the use of this material comes from the fact that them can control the transmission or light reflection, as well as control the transport of heat and selectivity of ultraviolet light. The condition for changing of their selectivity characteristics occur with the application of an electric current. Therefore, your application can spread to different areas, for example the products related to the automotive industry, construction, aerospace, military use, entertainment, among others. This fact arouses interest in research of new applications and the improvement of technique, as proposed in this work is the study of electrochromic material to a tubular lighting system. This proposal comes as a solution to assistance in temperature control and an ambient lighting, contributing to the quality level of illuminance and the climate of the location, factors that directly impact the reduction of the electricity cost.
\end{abstract}

\section{Key words}

Electrochromic, luminosity control, capture sunlight and low cost.

\section{Introduction}

The current routine of people show who they are present about $80-90 \%$ of their time in places such as buildings and in cars, emphasizing the importance of quality to these environments. For this, the electricity is widely used as a way to keep the places, comfortable and healthy [1] .

About $40 \%$ of electricity supply in Europe is used in buildings to keep the heating systems air conditioning equipment and other electrical equipment [2] In the Brazilian reality the residential sector is responsible for $21.2 \%$ of electricity consumption, the second largest energy consumer, behind only industrial sector, which accounts for $33.0 \%$ [3] .

Currently is a global necessity to develop technologies to reduce energy consumption, aiming to contribute energy matrix. In this reasoning, there is a very broad space for development of technologies for control of solar radiation flux and luminosity with low energy consumption. For this has been the use of called smart windows, which have the ability to regulate the transmission of luminosity and heat inside the environments [4] . 
The calls windows composed of electrochromic devices have variable transmittance, offering good contrast levels between internal and external environments. Like characteristics these materials minimize the passage of ultraviolet and infrared, resulting in a fall in heating indoors, moreover, it has the ability to regulate the transmission of light and heat reducing the use of components such as lamps and air conditioners that consume energy electrical [5] [6] .

The electrochromic material is an opto-electrochemical system having of their optical properties altered when subjected to a potential difference (V), the main state change is the transmittance. As mentioned earlier, this effect extends its application smart windows, sunroofs homes and automotive, eyeglass lenses, and mirrors and displays [7] .

Even with the technological development reached, the search for new materials and research to improve the performance of the devices are shown with high importance.

This article is a brief review about the different types of chromogens effects, reports the history of the development of electrochromic effect and a study of the materials currently used in the market. Will be presented current technology employed will be presented to the tubular lighting system, which is intended to use the electrochromic material to the backlight control and optimization of thermal comfort.

\section{State of Art}

\section{A. Electrochromic materials}

The electrochromic materials belong to class of chromogenic materials [8]. These materials are a class formed by different materials which change their optical properties with the interaction of some other material, they are [9] :

- Photochromic alter their optical properties on contact with light and reversing its initial state to be in the dark;

- Thermochromic, change their optical characteristics being in contact with elements that provide heat and returning to the initial state when cooling;

- Pressure, alter their optical properties due to pressure variation;

- Electrochromic alter their optical properties when an electric field is applied, reversing its initial condition with the reversal of the electric field;

- Gas, changing its color by a chemical reaction of a gas, having its original characteristic with the removal of gas;

- Liquid Crystals, these materials change the orientation of its molecules by applying an electric field, changing the optical absorption or mirror layers.

Given this range of chromogens materials, this work is directed to the study of electrochromic materials that are capable of regulating the transmission or reflection of light and heat, whereas a small voltage is applied to its conductors. A widely used system is made from five layers of thin films pressed between two glass substrates, as shown by Fig. 1

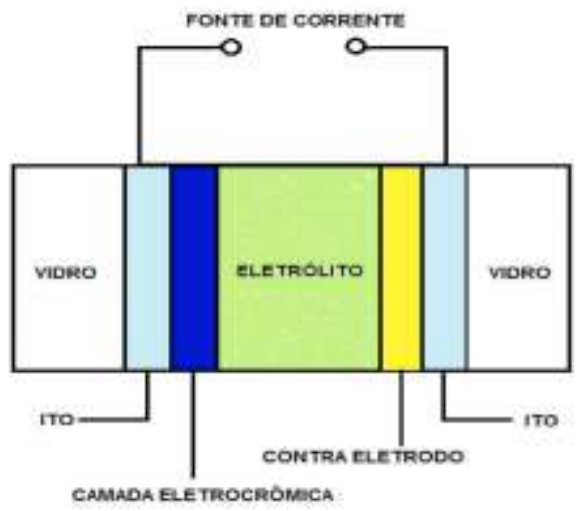

Fig. 1. Graphical representation of an electrochromic device [10]

The assembly of such films is accomplished by separately depositing the electrochromic film layers (electrochromic layer) and film reservoir of ions (counter electrode) on glass substrates covered by a transparent conductor (ITO). Finally the two parts are joined to isolate the layers of atmosphere and humidity [10], Ie the electrochromic device consists of two transparent conductive electrodes (ITO or FTO), and electrochromic material may be on one of the electrodes in film form or diluted in the electrolyte. The most widely used electrodes are the (ITO) doped with tin oxide and indium (FTO) tin oxide doped with fluorine [13] .

The operating principle of an electrochromic device is displayed in Fig. 2. Initially, the electrochromic material is translucent and receiving an electric charge, it undergoes a reduction reaction that causes the change of color, so that the electrolyte of the lithium ions are inserted into the electrochromic material. This color change (blue) example, is reversible and can still be created coloring stages by controlling the voltage level applied to electrodes [13] .

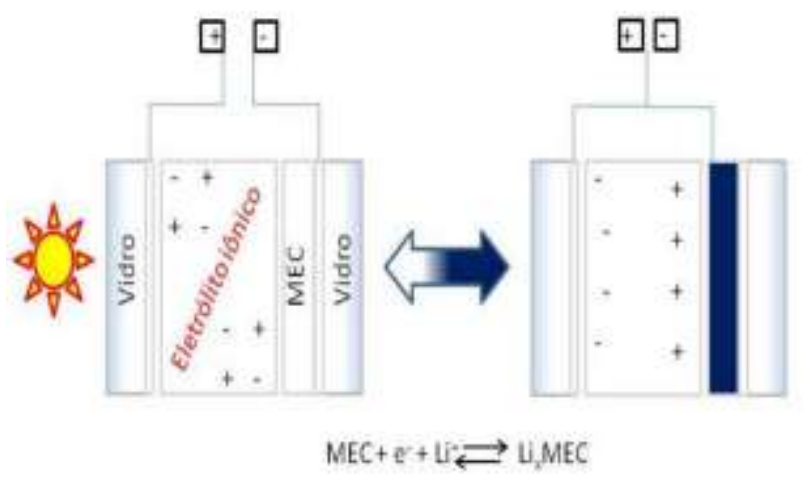

Fig. 2. Electrochromic device, operating principle with adaptation [13]

Depending on the material used, the electrochromic devices can work in transmission mode, in the case of smart windows or reflection mode as displays or mirrors [9] . 
Interestingly, many work on electrochromic materials are found and they have various configurations, because there are many techniques of deposition and clothing, making it difficult to compare quality among methods, since variables such as the size of the piece, transmittance, reflectance, staining and discoloration cycles are essential for device quality [9] [13] .

In practice, the application of the electrochromic technique results in the creation of electrochromic devices, but to characterize these devices used there are four parameters:

- High electrochromic efficiency $(\eta)$ is related to the amount of injected charge and the variation of the staining of the material.

- Optical Memory is on the ability of the material to keep their coloring even after being removed from the electrical contact.

- Short response time is related to the time it takes the material to change its color after contact with a source of electricity.

- Good stability and durability.

The electrochromic device requires that all these parameters are met. Compared to liquid crystal displays have several advantages such as high optical contrast with continuously variable transmittance regardless of the viewing angle, optical memory, stability to UVA and UVB rays and operation at high temperature ranges [5] [11] [14]

The perfect electrochromic window fits the different seasons of the year, especially in the toughest seasons, as the summer and winter [15]. The Fig. 3Fig. 3. It presents a schematic drawing of a perfect electrochromic window for both summer and for the winter period. The perfect window for the summer Fig. 3Fig. 3 (a), Is transparent to visible and light reflective solar radiation below 400nm and above $700 \mathrm{~nm}$, ie, thermal radiation generated within the environment can be transmitted to the external environment, however any heat generated on the outside and reflected letting only brightness in the environment. The window for the winter Fig. 3 (b) is fully transparent for the entire solar spectrum, and fully reflective for indoor and outdoor thermal radiation [13].

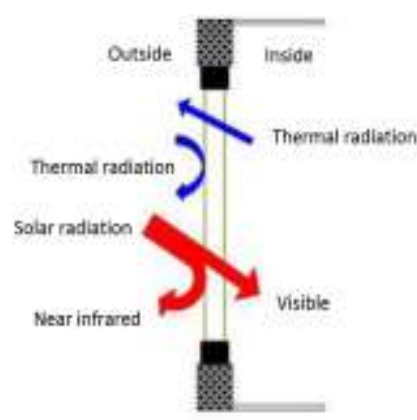

a) Window for summer

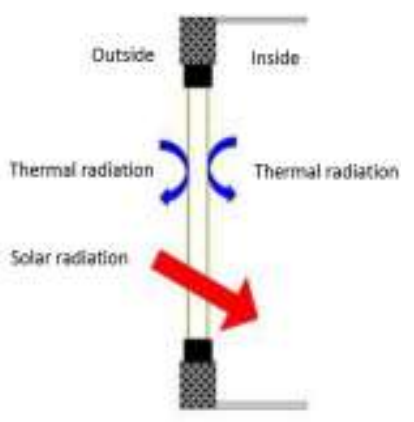

b) Window for winter
Fig. 3. Perfect electrochromic window [13]

In order to assess the performance of smart windows, due to the reduction of energy consumption, in 2006 was constructed a building at Lawrence Berkeley National Laboratory in Berkeley University [16] . The building has electrochromic windows installed, obtained a reduction of energy consumption for the lighting system between 6-
$25 \%$, in addition to reducing energy consumption with $19-26 \%$ cooling system. Among the studies, it has to be the energy saving buildings can achieve between $15-25 \%$ annually [16] .

The Fig. 4 presents an electrochromic window produced and installed in ChromoGenics Company in Uppsala, Sweden.

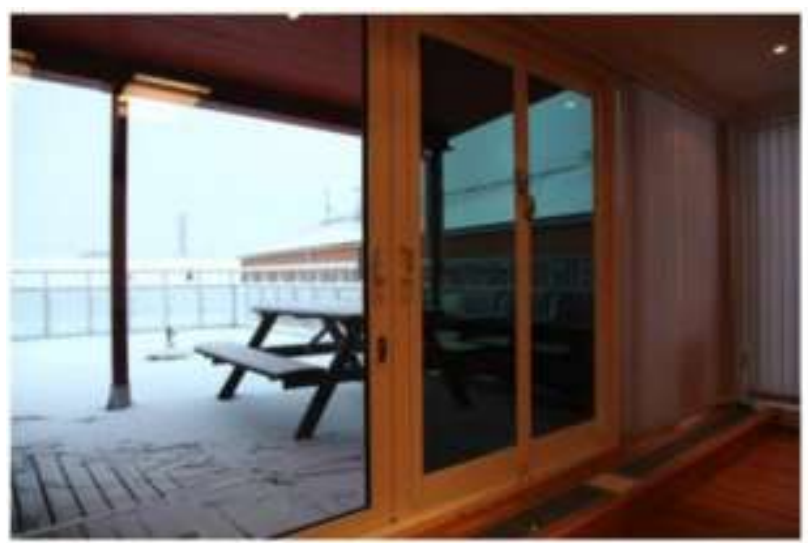

Fig. 4. Electrochromic window [17]

In 2013, there was a new study to explore and evaluate various practical aspects of the performance of the technology. Seeking to understand in detail the technology and verify the reduction of energy use for heating, ventilation and air conditioning (HVAC). The results show by the use of electrochromic windows have a reduction of $22 \%$ in annual use of HVAC, compared to conventional windows. Specifically, the cooling load decreased $45 \%$ and gas consumption decreased by $19 \%$ [16] .

The electrochromic devices have a huge range of application of this technology has some aspects which are already produced lenses for glasses, working in light and dark environments. On a commercial scale, companies like Ferrari in partnership with Saint-Gobain Sekurit developed an electrochromic sunroof, which through the touch of a button, the glass of the electrical system to permit the passage of light to the interior and can still having five other light transmission levels [13] .

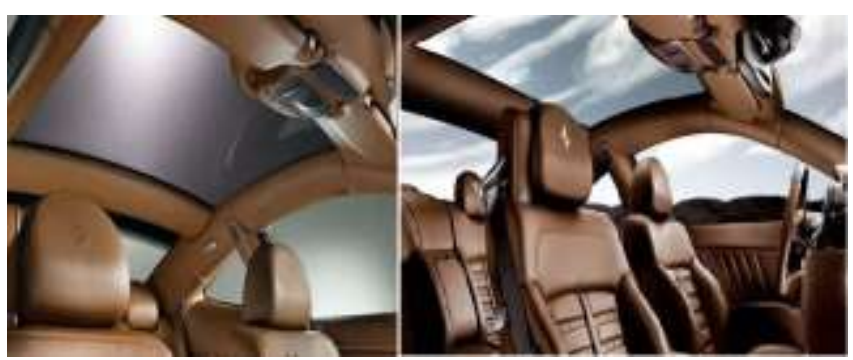

Fig. 5. Sunroof with electrochromic device [18]

Another commercial application are electrochromic mirrors that attenuate the light intensity reflected by them, offering more security to drivers avoiding the blurring of vision.

In Brazil there are in the automotive market some vehicles using electrochromic rear-view mirrors, including the Hyundai i30, Fiat Palio Adventure Locker, Chevrolet Omega [13] . Some examples of the electrochromic effect are shown in Fig. 6. 

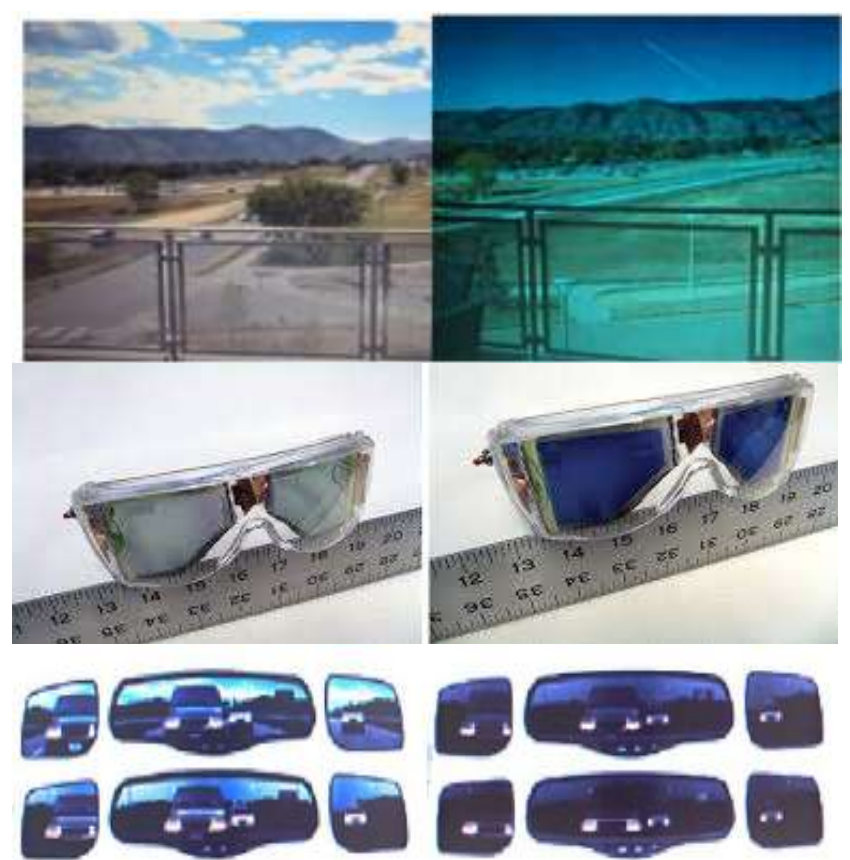

Fig. 6. Electrochromic devices, window glasses and rearview [4]

As show in Fig. 6, glasses with electrochromic technology does not completely blocks the view, they are designed to block unwanted sunlight, heat or adjust the brightness level, continuously preserving the vision.

At commercial level, there is that the market is led by a few companies such as Sage Electrochromics (USA), Research Frontiers (US), Saint Gobain (USA), Citalá (Israel), SmartGlass International Ltd (UK), Domoticware (Spain), RavenBrick, LLC (USA), Gentex Corporation (USA), Corning (USA) and OOO Control Systems (USA). Although the use of this technology was given "right" in the past decade, these predictions did not materialize, but its growth is imminent experts.

\section{B. System Tubular Lighting}

Some companies invest in development projects to capture and conduct of sunlight to the indoor environment. Collaborating for this development has been the use of highly efficient optical materials, making possible "technology of natural light guide" that can direct the solar rays to the desired location obtained with yields higher than $90 \%$. This technology is derived from specialized companies in the United States (Solatube) and Spain (Tubysol and Espacio Solar), manufacturing high quality products. These products are distributed by various countries, including Brazil [19] .

However, in Brazil, there are few places with this technology installed, because it is a high cost product for the Brazilian economic reality [20] .

The functioning of this type of lighting system is composed of three fundamental elements, as can be seen in Fig. 7, the dome is leased on the outside, has the function of receiving the sunlight and direct it into the tube. This is the conductor, it has highly reflective inner lining (can reach up to $99.7 \%$ ), he is responsible for transporting the natural light reaching the dome and submit the same for reflection to the diffuser lens (indoor), the lens in turn causes the dispersion of incoming rays, improving distribution and illuminating the environment.

[20] .

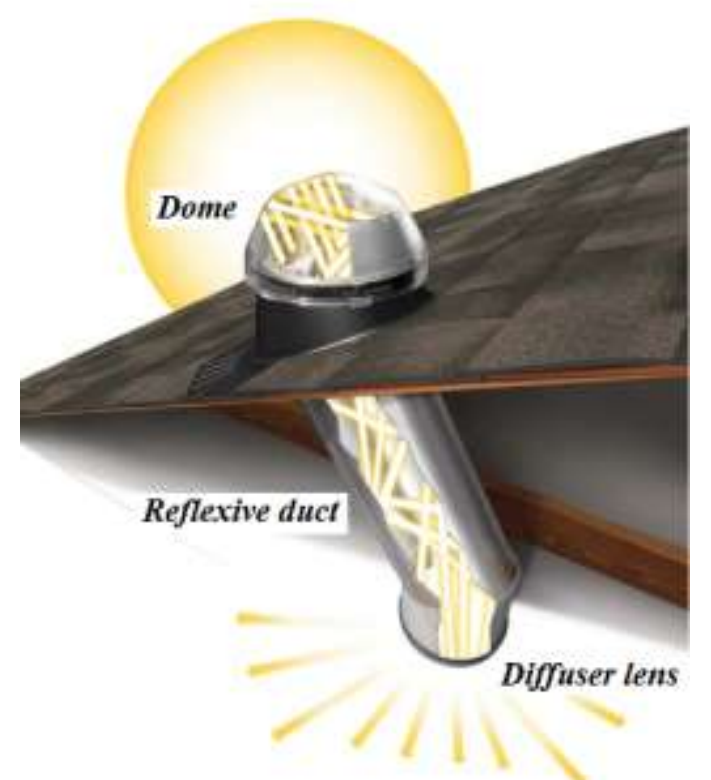

Fig. 7. Tubular lighting system [22]

Next will be exposed constructive features and functions of tubular lighting systems of the largest manufacturers in the industry. Which cited the Solatube and Espacio Solar Company.

\section{1) Dome}

The dome is the element responsible for capture and the direction of sunlight to the interior of the tubing. In a construction are used materials that enhance the capture of light, it is necessary to reconcile transparency for the transmission of rays, and mechanical strength to protect it from impact and weathering. A Fig. 8 represents industrialized domes by Solatube company that is made of polyester with UV treatment and Solar Espacio that developed in glass [19]

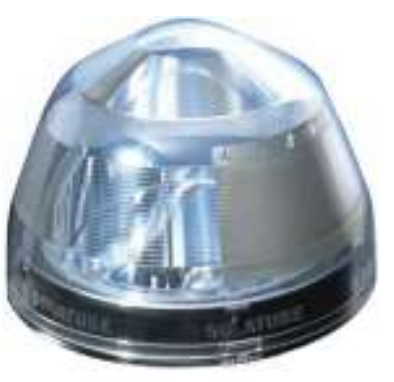

\section{Solatube}

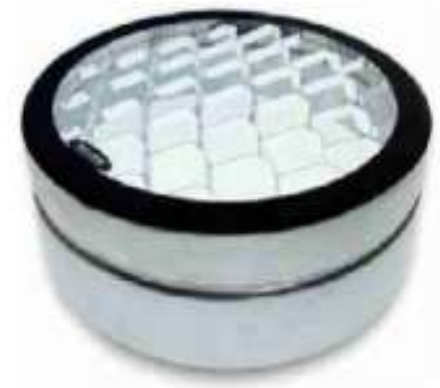

Espacio Solar
Fig. 8. Comercial Domes Solatube e Espacio Solar [21] [22] .

The domes are designed to enhance the capture and direction of sunlight, enjoying the sunlight to low angle, thus increasing the light gathering time [20] . 


\section{2) Reflexive duct}

The reflective ducts have the function of directing the incoming rays of the dome to the diffuser lens, the phenomenon featuring your feature is the internal reflection. These are designed to avoid the most reflective losses, causing, in some cases, the inner reach $99.7 \%$ reflectivity. Fig. 9 shows the pipe manufactured by Solatube, this aluminum and developed with the application of a proprietary internal film [19] [20] .

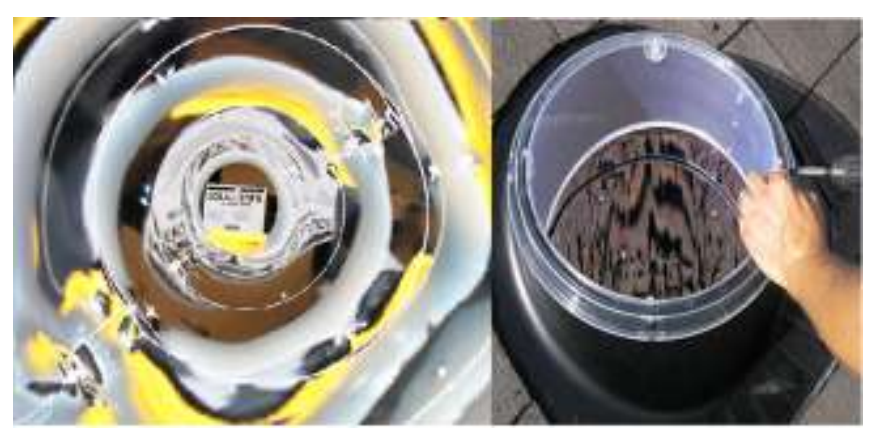

Fig. 9. Reflexive ducts [20]

The product manufactured by the company Solar Espacio is made of aluminum and receive a surface treatment on highly reflective silver with PVD technology - Silver-Plus Alanod, causing the reflective factor of the system reaches $98 \%[21]$.

\section{3) Diffuser lens}

The diffuser lens is the last element of the tubular lighting system, it serves to diffuse the light received from the reflective tube and illuminate the interior with quality of the environment, in addition, it also contributes to the thermal insulation and acoustic design [20]. This type of lens is made of polymeric material (acrylic) on either manufacturers that may be developed in various shapes, adapting this aesthetic modeling environment, as can be seen in Fig. 10 [19]

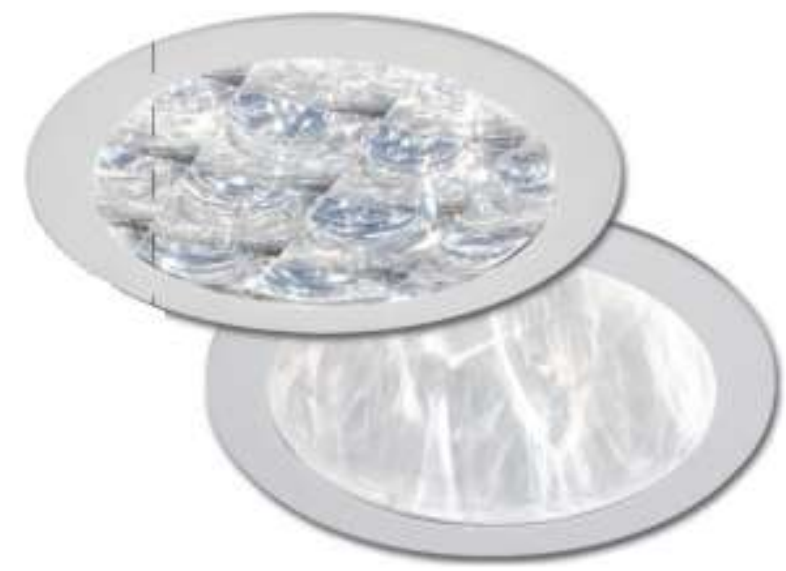

Fig. 10. Diffusing lens [22]

\section{Proposed system}

The tubular lighting system is commercialized foreign market, in countries like Spain, Portugal and the United States has the capacity to illuminate an environment that occurs without the consumption of electricity. This system has some limitations, which may be mentioned, the lack of lighting in periods when there is no solar radiation and ambient lighting level control system for both the lack of lighting as for excess sunlight. In a recent study, was developed a tubular system Hybrid lighting, where a circuit composed of LED's compensates the brightness level in the environment. This system was designed to focus on the use of recyclable and reusable materials, using components such as tempered glass, PVC pipes with reflective lining and a polycarbonate diffuser lens. This system also has an electronic circuit composed of an embedded system Arduino, which makes the monitoring of sun light received by a light sensor LDR, with these data it will brightness compensation lighting the LED's [20]

Looking for new alternatives to reduce consumption of electricity, this work presents the possibility of exchanging one of the components of the tubular lighting system. It is suggested to change the diffusion system, meaning, the exchange of the diffuser lens material, which is currently made and marketed polymeric material (acrylic).

For the new concept will use an electrochromic material, more precisely a electrochromic window, aiming the backlight control to the moments of high sunlight and also the attenuation in heat transmission conducted by reflective piping, another extremely important factor is selectivity ultraviolet UVA and UVB that provides the window.

The new diffuser lens will be installed at the same position of the currently marketed, and your control may be performed manually or automatically with the use of light and thermal sensors and a data processing system.

However the application of the electrochromic material to the tubular Natural Lighting system, will aim at contribute to the welfare of residents of the environment, as luminotécnico and thermal factor. This last one can be emphasized, since the characteristic of a perfect electrochromic window is to isolate the internal environment of heat from the external environment into cold climates and when in hot climates, it insulates the internal environment from the external heat and also contributes to the heat dissipation generated internally.

This application form can become reality, considering the low power consumption of the system, data shows that the smart window consumes $0,65 \mathrm{~W} / \mathrm{m}^{2}$, with a maximum current draw of $18 \mathrm{~mA} / \mathrm{m}^{2}$, with these small values can be achieved $95 \%$ in heat blockage in the dark mode and $57 \%$ in heat transfer in transparent mode, his ultraviolet protection is $99.9 \%$ for both color states. As for visible light transmission the proposal diffuser lens can block up to $99.96 \%$ and transmit $65 \%$ of light energy received [23] .

For this review were no limitations on the value for the use of electrochromic material, the study focused on replacement of diffuser lens to compose and add new features to the tubular system of natural lighting, improving this way the system currently marketed, contributed to the optical quality of the environment and consequently with a decrease in the consumption of electricity with thermal sources. 


\section{Conclusion}

This paper describes the development of technology of electrochromic devices, presenting its main constructive settings, some commercial applications, the effects and benefits of its use. Together, it was revised state of the art of tubular daylighting system, which has the characteristic light up a room without the consumption of electricity.

The objective of the research was to suggest a new application to the electrochromic device, more precisely an electrochromic window, where would replace the diffusion lens of the tubular lighting system. This change would add highest quality to the system, since the lens has greater selectivity for electrochromic ultraviolet and infrared, and has the ability to adjust the level of heat transfer and light transmission.

Having the tubular system of natural lighting as an efficient design, high level of lighting without energy consumption, combined with a system control of light and thermal of low power consumption, it creates an alternative to the development of a product with high efficiency energy, providing daylighting with controlled luminosity and heat, effectively contributing in the reduction of use of the cooling system and the quality of the environment.

Following some research, use of smart electrochromic devices is considered a promising way saving electricity. In view of this, the development of new technologies for the control of incident solar energy and light with low energy consumption, tend to grow a lot with the use of smart electrochromic device.

However, there are several alternatives for the implementation of electrochromic materials, where this can offer comfort, better quality of life people, as well as contribute to reducing the consumption of electricity. These facts become motivators for the development of technical, improving the production process and especially in the dissemination and access to consumers in general.

\section{Acknowledgement}

This project is being developed for under BAESA e ENERCAN for program of "Research and Development" regulated by ANEEL (3936-3314/2015). The authors would like thank to the BAESA and ENERCAN for supporting and facilities. The research presented, is in patent registration request phase in Brazil.

\section{References}

[1] S.O. Renato, S.O. Marcio R., O. Silvio C., e A.P. Eduardo, "Materiais Eletrocrômicos Orgânicos: Uma Breve Revisão de Viológenos, Ftalocianinas e Alguns Complexos de Metais de Transição", RVq 2013, ISSN 1984-6835.

[2] P. Arnaldo João, "Estudo de Tecnologias de Eficiência Energética na Reabilitação de Edifícios Domésticos", Dissertation University of Porto’s Engineering, Porto 2013.

[3] BEM, Available in: < https://ben.epe.gov.br/downloads /S\%C3\%ADntese\%20do\%20Relat\%C3\%B3rio\%20Final_2 015_Web.pdf>. Acessed: 30 out. 2015.
[4] S. Franciani C, "Desenvolvimento de janelas eletrocrômicas”, Doctoral thesis, São Paulo's University, São Carlos' Engineering School, 2012.

[5] De Mello, D.A.A., Oliveira, M.R.S., De Oliveira, L.C.S., De Oliveira, "S. C. Solid Electrolytes for eletrochromic devices based on reversible metal electrodeposition." Solar Energy Materials and Solar Cells, v 103, n, p.17-24, 2012.

[6] Engfeldt, J.D., Georen, P, Lagergren, C., Lindbergh, G.

"Methodology for measuring current distribuition effects in electrochromic smart windows" Applied Optics, v.50, n.29, 2011.

[7] Heusing, S., Aegeter, M.A., Sol-gel coatings for electrocrhomic devices, Ed. Sakka Aplication of Sol-gel Technology, Kluwer, Boston. 205

[8] Lampert C.M. and Granqvist C.G., "Large-Area Chromogenics: Materials and Divices for Transmittance Control" eds. C.M. Lampert and C.G. Granqvist, Vol. IS 4, 2, SPIE Optical Engineering Press, Bellingham 1990.

[9] Fabio F.F., "Eletrocromismo em Filmes Finos Compósitos", Doctoral thesis, Physics Institute of the São Paulo's University, 2003.

[10] Franciani C.S., "Desenvolvimento de Janelas Eletrocrômicas" Doctoral thesis, Graduate Inter Program in Materials Science and Engineering, São Paulo's University, 2012.

[11] Oliveira, S.C., Torresi, R.M., "Uma visão das tendências e perspectivas em eletrocromismo: a busca de novos materiais e desenhos mais simples. Química Nova, v. 23, n. 1,2000 .

[12] Ribeiro, A.S. "Síntese dos tiofenos substituídos e eletrodeposição de filmes poliméricos para aplicação em dispositivos eletrocrômicos. " Doctoral thesis, Institute of Chemistry, State University of Campinas, 2003.

[13] Oliveira, R.S., Semaan, F.S.; Ponzio, E.A. "Janelas Eletrocrômicas: Uma Nova Era em Eficiência Energética", RVQ, ISSN 1984-6835, 2015.

[14] Argun, A. A., Aubert, P.H., Thompson, B. C., Schwendeman, I. Gaupp, C. L., Hwang, J., Pinto, N. J., Tanner, D. B., MacDiarmid, A. G., Reynolds, J. R. "Multicolored Electrochromism in Polymers: Structures and Devices" Chemistry of Materials 2004, 16, 4401.

[15] Ye, H., Meng, X., Xu, B., "Theoretical discussions of perfect window, ideal near infrared solar spectrum regulating window and current thermochromic window", Energy and Buildings 2012, 49, 164.

[16] Sítio do Lawrence Berkeley National Laboratory. Available in :< http://windows.lbl.gov/comm_perf/Electr ochromic/refs/CEC- 500-2006-052_FinalReport.pdf >. Access: 29 Dez. 2015.

[17] Granqvist, C. G. "Electrochromics for smart windows: Oxide-based thin films and devices. Thin Solid Films" 2014, 564, 1 .

[18] Sítio do Paraná Online. Available in: <http://www.paranaonline.com.br/canal/automoveis/news/ 126205/>. Accessed on: 10 Jan 2016.

[19] Ando Junior, O. H., Rosa, H. B., Malfatti, C. F., Schaeffer, L., Spacek, A. D., Neto, J.M. " Sistema alternativo para iluminação de ambientes através da captação da luz sol." $3^{\text {a }}$ RenoMat - International Materials and Processes for Renewable Energy Conference, Porto Alegre - RS, 2013. 
[20] Ando Junior, O. H., Rosa, H. B., Spacek, A. D., Malfatti, C. F., Schaeffer, L., "Proposal of a Hybrid System for Solar and Photovoltaic for Lighting Low Cost". EA4EPQ, ICREPQ Córdoba Spain, 2014.

[21] ESPACIO SOLAR, Catalog Espacio Solar daylighting Available in: < http://espaciosolar.com /fichas.htm>. Access in: 6 Jan. 2016.

[22] SOLATUBE, Catalog Solatube daylighting - Available in: <http://www.solatube.com/es/productcatalog.htm>. Accessed on: 6 Jan. 2016

[23] SMARTGLASS, specifications - Available in: < http://www.smartglass.net.br/?page_id=10>. Accessed: 10 jan. 2016 